\title{
Assessing the exposure to formaldehyde of flooring installers during the installation of laminated flooring products
}

Viktar Lazouski ${ }^{1}$, Helen Heacock ${ }^{2}$

1. Lead Author, B. Tech Student, School of Health Sciences, British Columbia Institute of Technology, 3700 Willingdon Avenue, Burnaby.

2. Supervisor, School of Health Sciences, British Columbia Institute of Technology, 3700 Willingdon Avenue, Burnaby.

\section{ABSTRACT}

Background: Formaldehyde is a volatile organic compound (VOC) present in resins that bind the wood fibre core of laminated flooring products. Installation of laminate flooring involves performing certain procedures that increase the chance of formaldehyde volatilizing into the atmosphere. Exposure to formaldehyde can lead to acute health effects such as watery eyes, nausea, skin irritation, wheezing, and even death. Formaldehyde is also classified as a probable carcinogen and long-term exposure, even at lower doses, may lead to the development of cancers such as leukemia and sinus cancer.

Method: GASTEC formaldehyde 91D passive dositubes were used to quantify the concentrations of formaldehyde present at laminate flooring installation job-sites. The dositubes were worn by two installers who each completed 5 flooring installations over a 15-day period. Between the two installers, there were 3 jobs using Chinese-made laminate, 3 jobs using German-made laminate, and 4 jobs using Canadian-made laminate. A fresh dositube was attached to the belt or collar of each installer at the beginning of the work day and worn while the installer was present at the job-site. In total, 30 samples were collected to which conversion factors were applied to change the units from ppmhours to an 8-hour time-weighted average TWA. Comparisons were made between Chinese-made, Canadian-made, and German-made laminates and the mean of all 30 readings was compared to the Operational Safety and Health Administration (OSHA) 8hour TWA standard of $0.75 \mathrm{ppm}$.

Results: A one-sample T-test indicated that the mean concentration of formaldehyde that the test subjects were exposed did not exceed the $0.75 \mathrm{ppm}$ TWA standard $(p=0.000)$. Further analysis via ANOVA revealed that there was no statistical difference when comparing TWAs stemming from installation of Chinese-made, German-made, and Canadian-made laminate flooring $(\mathrm{p}=0.200)$.

Conclusion: Based on the results, it was concluded that flooring installers working for the Laminate Warehouse in Maple Ridge, BC, are not at risk of developing acute health effects from installing laminate flooring. However, the installers are still exposed to formaldehyde on a daily basis and chronic exposure could increase the risk of developing cancer. In addition, there was no observed relationship between origin of laminate flooring and levels of formaldehyde exposure.

Keywords: Laminate flooring, formaldehyde, passive dositubes, flooring installation, flooring installers, occupational hazard 


\section{INTRODUCTION}

Formaldehyde is a volatile organic compound that is ubiquitous in the environment (1). It is commonly produced from fossil fuel combustion, tobacco smoke, and the use of certain building materials (1). Acute exposure to lower concentrations of formaldehyde can produce health effects that include skin and respiratory tract irritation, impaired lung function, and eye irritation (2). Exposure to high concentrations of formaldehyde can lead to more serious complications such as unconsciousness, seizures, or even death (2). Additionally, because formaldehyde is classified as a probable carcinogen, chronic exposure, even at low doses, increases the risk of developing certain cancers such as leukemia and sinus cancer (3).

It is well established that formaldehyde is present in many wood-pressed products such as plywood, oriental strand board, baseboards, kitchen cabinets and laminate flooring (4). Wood-pressed products have an advantage over solid-wood products because manufacturing costs are much cheaper which translates to a much cheaper product for the consumer (5). The manufacturing process of these products involves combining pulverized wood-waste fibres with formaldehyde-containing glues and resins.

Two types of formaldehyde are commonly used in wood-pressed products - urea formaldehyde (UF) and phenol formaldehyde (PF) (6). These compounds are used primarily because of their low cost, resistance to microorganisms, excellent thermal properties, excellent binding properties, and lack of color (6). UF is used in the development of plywood, laminate flooring and other particleboard products (6). PF has excellent water-resistant properties and therefore it is mainly used in outdoor building materials (6). Most health concerns with formaldehyde emissions are due to UF products rather than PF products as the $\mathrm{PF}$ is consumed during the curing process and emission levels afterwards are negligible (6).

Over the last several decades there has been an increasing number of concerns regarding laminate flooring products emitting high and possibly dangerous levels of formaldehyde (7). These speculations are very concerning not only for consumers of laminated flooring products but also for flooring installers who work with laminated flooring products on a daily basis. As such, the purpose of this study was to analyze a flooring installer's exposure to formaldehyde throughout a typical day of installing laminate flooring. Measurements were compared to the Occupational Health and Safety (OSHA) formaldehyde exposure time-weighted average standard of $0.75 \mathrm{ppm}$ to determine if installers are at risk for overexposure (8). Additionally, formaldehyde emissions from Chinese, Canadian, and German-made laminates were compared.

\section{EVIDENCE REVIEW}

\section{Observed and recommended indoor levels of formaldehyde}

A study performed in 2005 analyzed 96 homes in Quebec for their indoor formaldehyde concentrations (9). It was concluded that formaldehyde concentrations ranged from 9.6 to $90 \mathrm{ug} / \mathrm{m}^{3}$ and that mobile homes contained the highest levels of formaldehyde because they have a larger 
proportion of wood pressed products in a smaller volume of space (9).

The Canadian Government published a set of indoor air quality guidelines to inform the public on the maximum levels of common indoor pollutants, including formaldehyde (10). The guidelines dictate that the maximum short-term exposure level to formaldehyde should be no greater than 120 $\mathrm{ug} / \mathrm{m}^{3}$ and the maximum long-term level should be no greater than $60 \mathrm{ug} / \mathrm{m}^{3}$ (10).

Within an occupational setting, Operational Safety and Health Administration (OSHA) sets the permissible exposure limit to be $0.75 \mathrm{ppm}$ which is measured as an 8 -hour time weighted average (TWA) (8). For short-term exposure, based on a 15-minute TWA, the permissible limit is 2 ppm (8). The action level at which increased industrial hygiene monitoring should be implemented and worker medical surveillance should be initiated is $0.5 \mathrm{ppm}$, also calculated as an 8-hour TWA (8).

\section{Regulation of formaldehyde emissions in North America}

Regulations regarding formaldehyde emissions from wood-pressed products vary across North America. To control formaldehyde emissions from wood-pressed products sold in the US, in 2016, the US congress signed into law the Standards for Composite Wood Products as Title VI of the Toxic Substances Control Act (TSCA) (11). This regulation enforces all wood-pressed products imported and sold in the United States to comply with emission standards developed by the California Air Resource Board (CARB) (11). Title VI of the TSCA also enforces testing requirements, product labelling, chain of custody documentation, enforcement, and import certification of all wood-pressed products (11). CARB emission limits can be seen at the bottom of figure 1 . When compared to emission standards in other countries, as can be seen at the top of figure 1, CARB standards for laminate particleboard are much more strict than maximum emission levels of the European standard (0.09 compared to 0.14 ppm). A reason for this is that CARB standards are based on emission caps, whereas the European standard is based on averages.

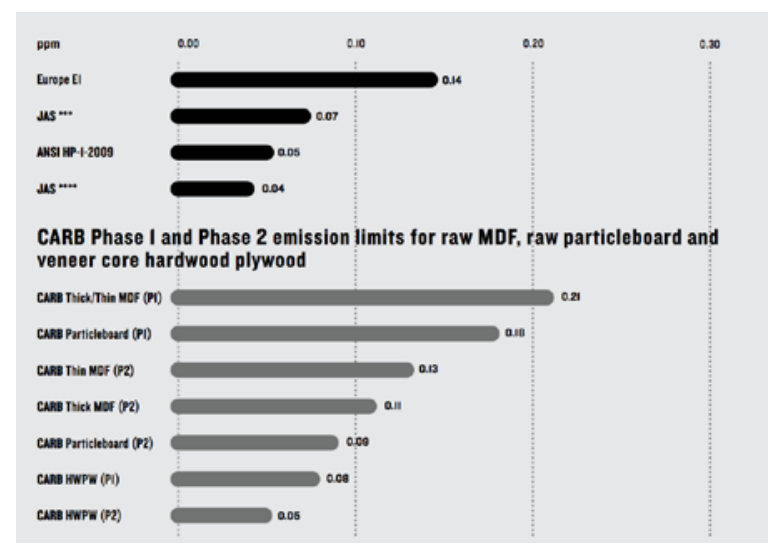

Figure 1: Comparison of CARB emission standards to the standards in other regions of the world (12).

Currently in Canada, there is no federal or provincial legislation to control emissions from wood-pressed products (13). However, in March of 2017, a notice of intent was published in Canada Gazette that the Department of Environment and the Department of Health are initiating the development of regulations against formaldehyde emissions (13). The two departments are in the process of acquiring feedback from stakeholders and it could take several years before a regulation will be approved (13).

\section{Laminate flooring imported from China}

Currently, every year, there are millions of square feet of flooring imported from China to North America (14). Laminate flooring 
imported from China is the most popular and also the cheapest flooring on the market as production costs are very low compared to that in Europe or North America. Unfortunately for Canadians, because there are no regulated emission standards, the potential for imported flooring products that contain high emissions of formaldehyde is very high.

The US Product and Safety Commission Agency for Toxic Substances performed an investigative study on imported Chinese flooring products and found many contraventions to prescribed US regulations such as mislabeling and very high emissions of formaldehyde (6). As a result, there have been several class-action law suits filed and approximately 30 million square feet laminate taken off the market $(6,14)$. In addition, a popular news show, 60 -minutes, performed their own investigative study on 31 high density fiberboard (HDF) and medium density fiberboard (MDF) products imported from China and found that 31 exceeded the CARB standard for emissions by up to 13 -fold in some cases (6). This particular incident kicked off a backlash amongst consumers and put a major halt on the Chinese flooring market in North America.

\section{Formaldehyde exposure during flooring installations}

Laminate flooring installers are at an increased risk of being exposed to dangerous levels of formaldehyde on a daily basis. Not only do installers work with fresh laminate right out of the box, they install on their hands and knees with their nose and mouth in close proximity to the flooring. The installation process also requires many laminate planks to be cut, especially when starting or finishing a row, installing around wall corners, and installing on stairs. A chop saw is the most commonly used tool for cutting laminate planks due to its speed and precision, however, it is also the messiest tools as wood and glue particulates are released into the air (15).

Most flooring manufacturers include a warning in every box of laminate flooring that advises installers to wear protective equipment on the job site, but many rarely do. Two reasons provided against wearing protective equipment is that it is too restrictive and that the risk of exposure to toxic substances during installations is perceived to be minimal.

\section{METHODOLOGY}

The study required two laminate flooring installers, employed by the Laminate Warehouse in Maple Ridge, BC, to each wear GASTEC 91D formaldehyde passive dositubes over the course of 5 installation jobs. Each installer attached a fresh dositube to either their collar or belt at the beginning of each installation day. The two installers worked independently of each other and were test subjects for 15 installation days each. Installer \#1 had 3 jobs with Chinesemade laminate spanning 8 installation days, 1 job with Canadian-made laminate spanning 3 installation days and 1 job with German-made laminate spanning 4 installation days. Installer \#2 had 3 jobs with Canadian-made laminate spanning 9 installation days and 2 jobs with Germanmade laminate spanning 6 installation days. Additionally, at every job-site, a control dositube was placed in a room that did not receive new flooring to record background levels of formaldehyde.

The installers were asked to not take the dositubes off-site, such as when leaving to grab lunch. If the installers were to leave the job-site, they were asked to put a piece of tape over the broken dositube end so it did 
not absorb formaldehyde while not attached to the installer. Also, at the end of each day, the installers were asked to record their hours spent on the job-site, as well as the length of color change on the tube which indicates the degree of exposure in ppmhours. In order to compare the measurement to the OSHA standard, the ppm-hours measurement needed to be converted into a TWA with the following formula (16):

TWA $=$ (ppm-hours reading on dositube) (hours worked)

After calculating the TWA in ppm, because the OSHA TWA standard is based on an 8hour work shift, a correction factor needed to be applied for the installation workdays over or under 8 hours in length (17). The following is the formula for the correction factor:

Correction factor $=\frac{8}{h} \times \frac{(24-h)}{16}$

(Where $\mathrm{h}=$ hours spent at job-site)

\section{$\underline{\text { RESULTS }}$}

30 formaldehyde measurements were obtained from the study -15 measurements for installer \#1 and 15 measurements for installer \#2. Installer \#1 was exposed to formaldehyde during all 15 days of installations whereas installer \#2 was exposed to formaldehyde 14 out of the 15 installation days (tables 1 and 2). Exposure did not occur on day 12 because the installer only had a 2-hour work day that did not involve installing, cutting or gluing laminate planks. Furthermore, the mean, median, and mode of all 30 measurements was $0.25 \mathrm{ppm}$ (table 3). The greatest exposure for installer \#1 was during the installation of Chinesemade laminate where formaldehyde levels reached $0.44 \mathrm{ppm}$. For installer \#2, the greatest exposure was during the installation of German-made laminate where formaldehyde levels reached $0.41 \mathrm{ppm}$. Further statistical analyses were computed with NCSS software (18).

Table 1: Installer \#1 data

\begin{tabular}{|c|c|c|c|}
\hline $\begin{array}{c}\text { Job 1 - } \\
\text { Chinese }\end{array}$ & $\begin{array}{c}\text { ppm- } \\
\text { hours }\end{array}$ & $\begin{array}{c}\text { hours } \\
\text { exposed }\end{array}$ & $\begin{array}{c}\text { corrected } \\
\text { TWA }\end{array}$ \\
\hline Day 1 & 1.5 & 7.5 & 0.22 \\
Day 2 & 2.5 & 7.5 & 0.37 \\
Day 3 & 2 & 8.5 & 0.21 \\
\hline Job 2 - & ppm- & hours & corrected \\
Chinese & hours & exposed & TWA \\
\hline Day 4 & 2 & 8 & 0.25 \\
Day 5 & 1.5 & 8.25 & 0.17 \\
Day 6 & 3 & 9 & 0.28 \\
\hline Job 3 - & ppm- & hours & corrected \\
Chinese & hours & exposed & TWA \\
\hline Day 7 & 3 & 7.5 & 0.44 \\
Day 8 & 2 & 7.75 & 0.27 \\
\hline Job 4 - & ppm- & hours & corrected \\
Canadian & hours & exposed & TWA \\
\hline Day 9 & 1.5 & 7.5 & 0.22 \\
Day 10 & 2 & 8 & 0.25 \\
Day 11 & 1 & 9 & 0.09 \\
\hline Job 5 - & ppm- & hours & Corrected \\
German & hours & exposed & TWA \\
\hline Day 12 & 1 & 8 & 0.12 \\
Day 13 & 2.5 & 8 & 0.31 \\
Day 14 & 1.5 & 7.5 & 0.22 \\
Day 15 & 2 & 8 & 0.25 \\
\hline & & & \\
\hline
\end{tabular}

Table 2: Installer \#2 data

\begin{tabular}{|c|c|c|c|}
\hline $\begin{array}{c}\text { Job 1 - } \\
\text { Canadian }\end{array}$ & $\begin{array}{c}\text { ppm- } \\
\text { hours }\end{array}$ & $\begin{array}{c}\text { hours } \\
\text { exposed }\end{array}$ & $\begin{array}{c}\text { corrected } \\
\text { TWA }\end{array}$ \\
\hline Day 1 & 3 & 7.5 & 0.18 \\
Day 2 & 2.5 & 8 & 0.30 \\
Day 3 & 0.5 & 4 & 0.31 \\
\hline Job 2 - & ppm- & hours & corrected \\
Canadian & hours & exposed & TWA \\
\hline Day 4 & 2.5 & 8.25 & 0.29 \\
Day 5 & 2 & 7 & 0.35 \\
Day 6 & 3.5 & 8.5 & 0.38 \\
\hline Job 3 - & ppm- & hours & corrected \\
Canadian & hours & exposed & TWA \\
\hline Day 7 & 2 & 8 & 0.25 \\
Day 8 & 3 & 8 & 0.38 \\
Day 9 & 3 & 8.5 & 0.32 \\
\hline Job 4 - & ppm- & hours & corrected \\
German & hours & exposed & TWA \\
\hline Day 10 & 3 & 7.75 & 0.41 \\
Day 11 & 1.5 & 8 & 0.19 \\
Day 12 & 0 & 2 & 0
\end{tabular}




\begin{tabular}{|c|c|c|c|}
\hline $\begin{array}{c}\text { Job 5 - } \\
\text { German }\end{array}$ & $\begin{array}{c}\text { ppm- } \\
\text { hours }\end{array}$ & $\begin{array}{c}\text { hours } \\
\text { exposed }\end{array}$ & $\begin{array}{c}\text { corrected } \\
\text { TWA }\end{array}$ \\
\hline Day 13 & 2 & 8.5 & 0.21 \\
Day 14 & 1.5 & 8 & 0.19 \\
Day 15 & 0.5 & 5 & 0.19 \\
\hline
\end{tabular}

Table 3: Descriptive statistics of all formaldehyde measurements

\begin{tabular}{|lr|}
\hline Mean & 0.254 \\
Median & 0.25 \\
Mode & 0.25 \\
Rtandard Deviation & 0.096475832 \\
Minimum & 0.44 \\
Maximum & 0 \\
Sum & 0.44 \\
Count & 7.62 \\
\hline
\end{tabular}

\section{DISCUSSION}

Exposure for both installers did not exceed the occupational standard of $0.75 \mathrm{ppm}$ OSHA standard on any installation day $(p=0.000)$. This means that the risk for developing acute health effects such as watery eyes, nausea, skin irritation, wheezing, or even death during installation of laminate flooring is minimal. However, it is important to note that formaldehyde is classified as a probable carcinogen to which there is no "acceptable" dose that will not cause a carcinogenic effect in the human body (19). As such, chronic exposure to formaldehyde, even at low doses, may increase the risk of developing certain cancers such as leukemia and sinus cancer.

The study also compared formaldehyde emissions from three different flooring types: Chinese-made, Canadian-made, and German-made laminate. Based on previous studies, Chinese-made laminate was theorized to not only have greater formaldehyde emissions than flooring manufactured in other locations, but also emissions that would exceed regulatory requirements (6). Canadian and Germanmade laminates are considered as top tier laminates and therefore were expected to have much lower emissions (20). The results of the study indicate that the mean concentration of formaldehyde the installers were exposed to during the installation of Chinese-made laminate flooring was 0.28 ppm, 0.28 ppm for Canadian-made flooring, and $0.21 \mathrm{ppm}$ for German-made flooring. Statistical analysis indicated that there is no statistical difference in formaldehyde emissions from the three flooring types $(p=0.200)$.

The results of this study are considered to be valid for several reasons. First, the installers were trained to use the detector tubes properly and were followed up with on a daily basis to ensure there were no technical difficulties. Second, by using control detector tubes at every job-site, background sources of formaldehyde were accounted for. These sources include kitchen cabinets, wall paint, and wood-pressed furniture. Validity is further increased because the detector tubes used in this study are manufactured by GASTEC. This company is a leader in the development of measuring devices and holds a Quality Assurance System Certification that ensures all of their measurement devices are manufactured to the highest standard (21). Their detector tubes are highly precise and accurate and are used by many agencies for environmental assessment purposes (22).

\section{KNOWLEDGE TRANSLATION}

The results from this study are of particular interest to the Laminate Warehouse business. Currently, they do not have any protocols in place to ensure that exposure to formaldehyde is minimized. For most 
flooring installations, their installers do not wear any personal protective equipment to protect themselves from formaldehyde gas and formaldehyde-containing particulate matter. The results of this study, therefore, can be used as evidence to show that there is in fact an elevated level of formaldehyde present at flooring job-sites. Even though the observed concentrations may not pose an immediate health concern, long-term exposure can still have detrimental effects on the human body. As such, installers can be encouraged to use personal protective equipment such as an N95 gas-mask while installing laminate flooring.

\section{LIMITATIONS}

One limitation of this study is that the results cannot be generalized to all flooring installers. Other flooring businesses may sell products that emit different amounts of formaldehyde, if any at all (some flooring products are guaranteed to have zero formaldehyde emissions). As such, flooring installers working for other flooring businesses will be exposed to levels of formaldehyde that are different than those stemming from products sold at the Laminate Warehouse. In addition, other businesses may have different installation protocols that would reduce exposure to formaldehyde such as making sure installers use a guillotine-style laminate cutter as opposed to a chop-saw that produces a considerable amount of airborne dust. To overcome these differences, a greater number of flooring businesses could be involved in the study so that a greater variety of products and installers are examined.

\section{FUTURE RESEARCH}

- Analyze formaldehyde emissions from laminates sold at retail locations other than Laminate Warehouse.

- Compare exposure to formaldehyde when using a chop-saw versus a guillotine-style laminate cutter.

- Measure VOC exposure when refinishing solid hardwood flooring. CONCLUSION

The results of this study indicate that during installation of laminated flooring products sold by the Laminate Warehouse, flooring installers are exposed to a concentration of formaldehyde that is below the $0.75 \mathrm{ppm}$ OSHA 8-hour TWA standard. This means that the development of acute health effects from installing laminated flooring products is minimal. Nevertheless, exposure to formaldehyde over a long period of time can still increase the risk of developing certain cancers and so precautions should still be taken when installing laminate flooring. Furthermore, the results indicate that there is no statistical difference in formaldehyde exposure levels stemming from the three examined flooring types: Chinese-made, German-made, and Canadian-made laminate, hence they can all be used with the same confidence that they are equally safe in terms of VOC emissions.

\section{ACKNOWLEDGEMENTS}

This research project was supported by the British Columbia Institute of Technology and the program for Environmental Health.

\section{COMPETING INTERESTS}

The authors declare that they have no competing interests.

\section{REFERENCES}

1. Health Canada. Consultation on the proposed regulatory approach to 
reduce emissions of formaldehyde from composite wood products [Internet]. [Accessed: October 20, 2017] Retrieved from:

http://www.ec.gc.ca/lcpecepa/default.asp?lang $=\mathrm{En} \& \mathrm{n}=00 \mathrm{~B} 2 \mathrm{~F}$ 79C-1\#s6 3

2. Environmental Protection Agency. Facts About Formaldehyde. [Internet]. n.d. [Accessed: November 26, 2017]. Retrieved from: https://www.epa.gov/formaldehyde/f acts-about-formaldehyde\#whatare

3. American Cancer Society. Formaldehyde. [Internet]. n.d. [Accessed: April 10, 2018]. Retrieved from: https://www.cancer.org/cancer/cance r-causes/formaldehyde.html

4. Rovira et. al. Human health risks of formaldehyde indoor levels: An issue of concern [Internet]. Journal of Environmental Science and Health, 2016 [Accessed: April 10, 2018], 51(4), 357-363, Retrieved from: https://www.ncbi.nlm.nih.gov/pubme $\mathrm{d} / 26785855$

5. Display2Go. Comparing Building Materials: Particleboard, MDF, \% Plywood. [Internet]. n.d. [Accessed: April 7, 2018]. Retrieved from: https://www.displays2go.ca/Guide/C omparing-Building-MaterialsParticle-Board-MDF-Plywood-17

6. Pierce et al. An Assessment of Formaldehyde Emissions from Laminate Flooring Manufactured in China [Internet]. Regulatory Toxicology and Pharmacology, 2016 [Accessed: October 19, 2017], 81, pp. 20-32, Retrieved from: doi:10.1016/j.yrtph.2016.06.022.

7. CTV News Winnipeg. Some Laminate Floors Emit Formaldehyde: Consumer Reports [Internet]. 2016. [Accessed: April 11,
2018]. Retrieved from: https://winnipeg.ctvnews.ca/somelaminate-floors-emit-formaldehydeconsumer-reports-1.3006949

8. Occupational Health and Safety Administration. Formaldehyde Fact Sheet. [Internet]. 2011. [Accessed: November 26, 2017]. Retrieved from: https://www.osha.gov/OshDoc/data General_Facts/formaldehydefactsheet.pdf

9. Dales et al. Public Health: Quality of Indoor Residential Air and Health [Internet]. CMAJ, 2008 [Accessed: October 20, 2017], 179(2), pp. 14752, Retrieved from: doi:10.1503/cmaj.070359.

10. Health Canada. Exposure Guidelines for Residential Indoor Air Quality [Internet]. 1987 [Accessed: October 20,2017]. Retrieved from: http://publications.gc.ca/collections/ Collection/H46-2-90-156E.pdf

11. Health Canada. Consultation on the proposed regulatory approach to reduce emissions of formaldehyde from composite wood products [Internet]. [Accessed: October 20, 2017]. Retrieved from: http://www.ec.gc.ca/lcpecepa/default.asp?lang $=$ En\&n $=00 \mathrm{~B} 2 \mathrm{~F}$ 79C-1\#s6_3

12. Columbia Forest Products, Frequently Asked Questions About CARB's New Regulations for Formaldehyde in Composite Wood Products [image on the internet]. 2011 [Accessed: October 20, 2017] Retrieved from: http://www.columbiaforestproducts.c om/wpcontent/uploads/2013/12/CAR B_Customer_FAQ.pdf

13. Health Canada, Environment and Climate Change Canada. Consultation on the Proposed 
Regulatory Approach to Reduce

Emissions of Formaldehyde from Composite Wood Products [Internet]. 2017 [Accessed: October 20, 2017]. Retrieved from: http://www.ec.gc.ca/lcpecepa/default.asp?lang $=$ En $\& n=00 \mathrm{~B} 2 \mathrm{~F}$ 79C-1\#s2_1

14. Floor Covering News. Laminate: US sales rise, Chinese imports decline [Internet]. 2016 [Accessed: October 20, 2017]. Retrieved from: http://www.fcnews.net/2016/06/lami nate-u-s-european-sales-rise-chineseimports-decline/

15. Marshall. Flooring installers beware of health risks: excessive levels of formaldehyde in Lumber Liquidators' flooring [Internet]. 2015 [Accessed: January 6, 2016]

Retrieved from: https://www.weitzlux.com/blog/2015 /09/16/flooring-installers-bewarehealth-risks-excessive-levelsformaldehyde-lumber-liquidatorsflooring/

16. GASTEC. \#91D: Passive Dosi-Tube for Formaldehyde. [Internet]. n.d. [Accessed: November 26, 2017]. Retrieved from: http://www.nextteq.com/pdfs/Gastec Tube Instructions 91D.pdf

17. Kieth Herle. ENVH 3500: TLVs Continued. [Lecture notes]. 2016. Presented at: BCIT

18. NCSS L. NCSS Statistical Software [Internet]. [Accessed: March 18, 2018]. Retrieved from: http://www.ncss.com

19. Qian Ding et al. Setting Risk-Based Occupational Exposure Limits for No-Threshold Carcinogens [Internet]. Human and Ecological Risk Assessment: An International Journal, 2014 [Accessed: March 18, 2018] 20:5, pp. 1329-1344.
Retrieved from:

https://www.tandfonline.com/doi/full /10.1080/10408440902810329?scroll $=$ top $\&$ needAccess $=$ true

20. Diverse Flooring. Flooring Made in China vs. Flooring Made in North America and Europe [Internet]. [Accessed: March 18, 2018]. Retrieved from: http://www.diverseflooring.ca/blog/a rticles/Flooring-Made-in-China-vsFlooring-Made-in-North-Americaand-

Europehttp://www.diverseflooring.ca /blog/articles/Flooring-Made-inChina-vs-Flooring-Made-in-NorthAmerica-and-Europe

21. GASTEC. Certifications. [Internet] n.d. [Accessed: March 18, 2018]. Retrieved from: https://www.gastec.co.jp/en/compan y/evaluation/

22. GASTEC. Gas detector tubes (and some relevant industrial standards). [Internet] n.d. [Accessed: March 18, 2018]. Retrieved from: https://www.gastec.co.jp/en/technolo gy/detector tube/summary/ 
